\title{
Does senile impairment of cholinergic system in rats concern only disturbances in cholinergic phenotype or the progressive degeneration of neuronal cell bodies? ${ }^{*}$
}

\author{
Grażyna Niewiadomska ${ }^{\bowtie}$, Jolanta Wyrzykowska and Magdalena Chechłacz \\ Department of Neurophysiology, Nencki Institute, Warszawa, Poland
}

Received: 22 May, 2000

Key words: nerve growth factor, basal forebrain, cholinergic neurons morphology and phenotype, plasticity, aging

\begin{abstract}
The trophic effect of continuous intraventricular infusion of nerve growth factor (NGF) on morphology of the basal forebrain (BF) cholinergic neurons was tested in 4and 28-month-old male Wistar rats. All studies were conducted using behaviorally uncharacterized animals from the same breeding colony. Immunohistochemical procedure for choline acetyltransferase (ChAT) and $\mathrm{p}^{\mathrm{NTR}}$ receptor has been applied to identify cholinergic cells in the structures of basal forebrain (BF). Using a quantitative image analyzer, morphometric and densitometric parameters of ChAT- and p75 ${ }^{\text {NTR }}$-positive cells were measured immediately after cessation of NGF infusion. In 28-month-old non-treated rats the number of intensively ChAT-positive cells in all forebrain structures was reduced by $50-70 \%$ as compared with young animals. The remaining ChAT-positive cells appeared shrunken and the neuropil staining was markedly reduced. In contrast, the same neurons when stained for $\mathrm{p} 75^{\mathrm{NTR}}$ were numerous and distinctly visible with perfect morphology. Analysis of Nissl stained sections also showed that 28-month-old rats did not display significant losses of neuronal cell bodies. NGF restored the number of intensely stained ChAT-positive cells to about $90 \%$ of that for young controls and caused a significant increase in size of those cells in 28-month-old rats as compared with the control, age-matched group. NGF did not influence the morphology of $75^{\mathrm{NTR}}$-positive neurons, which were well labeled, irrespective of treatment and age of the rats. In 4-month-old rats, NGF infusion decreased the intensity of both ChAT and p75 ${ }^{\mathrm{NTR}}$ immunostaining. These data provide some evi-
\end{abstract}

\footnotetext{
${ }^{\$}$ This research was supported by grant No. 4 PO5A 01415 from the State Committee for Scientific Research.

${ }^{凶}$ Correspondence should be addressed to: Grażyna Niewiadomska, Department of Neurophysiology, Nencki Institute, L. Pasteura 3, 02-093 Warszawa, Poland; e-mail: gwn@nencki.gov.pl

Abbreviations: AcHE, acetylcholinesterase; BF, basal forebrain; ChAT, choline acetyltransferase; DAB, diaminobenzidine; $\mathrm{Me}_{2} \mathrm{SO}$, dimethylsulfoxide; MS, medial septum; NBM, magnocellular basal nucleus; NGF, nerve growth factor; ROD, relative optical density; VDB and HDB, vertical and horizontal limb of the diagonal band; respectively.
} 
dence for preservation of BF cholinergic neurons from atrophy during aging and indicate that senile impairment of the cholinergic system in rats concerns decrease in ChAT-protein expression rather than an acute degeneration of neuronal cell bodies. Treatment with NGF resulted in restoration of cholinergic phenotype in the BF neurons of aged rats. However, the present study also rises issue of possible detrimental effects of NGF in young normal animals.

Much present-day neurobiological research points to the difference between normal and pathological aging of the nervous system (Dani et al., 1997). Normal aging is generally regarded as involving mild morphological, biochemical and physiological changes, which lead to slowing down of the normal function of the nervous system. The results of pathological aging are the neurodegenerative diseases, defined as progressive loss of neurons and extensive deterioration of cognitive and intellectual functions. During normal aging selective degeneration of neurons occurs in some parts of the cortex and non-cortical areas of the brain. However, there is in fact no substantial evidence that neuronal loss appears on a large scale as a universal effect throughout the whole brain. It is estimated that, in the cortex, very few neurons become lost with age (Cragg 1975; Pakkenberg \& Gundensen, 1997; Peters et al., 1998), and that this does not drastically affect cortical functions. Moreover, the effect of normal aging on the subcortical nuclei that modulate the function of neocortical regions is still incompletely understood.

A similar caution should be applied to the basal forebrain cholinergic system which plays an important role in learning and attentional processes of mammalian central nervous system. In rodents an age-dependent decline in acetylcholine synthesis (Dravid, 1993; Gibbson \& Peterson, 1981; Springer et al., 1987; Strong et al., 1990), acetylcholine release (Rama Sastry et al., 1983) and high-affinity choline uptake (Gilad et al., 1987) have been observed in various forebrain regions, and there is morphological evidence of cholinergic neuron atrophy, which in some cases is accompanied by cell loss, in the septal-diagonal band area, nucleus basalis and striatum (Dekker et al., 1992; Altavista et al.,
1990). Degeneration of basal forebrain cholinergic neurons is also found in aged nonhuman primates (Flood \& Coleman, 1988; Hayashi, 1996) and in patients suffering from Alzheimer's disease (Whitehous et al., 1982; Allen et al., 1988; Francis et al., 1994). Progressive loss of cholinergic neuronal functions during aging is frequently associated with learning and memory impairment suggesting that normal cognitive function is dependent on integrity of the central cholinergic ascending system (Gallagher \& Pelleymounter, 1988; Mandel et al., 1989; Olton et al., 1991).

Proper function of cholinergic neurons is dependent on a continuous supply of target-derived trophic factors such as the nerve growth factor (NGF) (Korsching, 1986; Thoenen et al., 1987; Whittemore \& Seiger, 1987; Sofroniew \& Cooper, 1993; Knusel \& Hefti, 1993). These neurons express NGF receptors, TrkA and p75 ${ }^{\text {NTR }}$ (Koh et al., 1989; Schattemann et al., 1988) and respond to NGF by increased activity of the acetylcholine synthesizing enzyme, choline acetyltransferase (ChAT) (Mobley et al., 1985; Cavicchioli et al., 1989; Hefti et al., 1989; Martinez et al., 1989). In NGF and TrkA knockout animals basal forebrain cholinergic neurons persist but they appear to be atrophic and show reduced synthesis of choline acetyltransferase and reduced axonal branching (for review see Snider, 1994). Although target-derived NGF does not regulate the survival of mature cholinergic neurons, the existent evidence suggests that the production of ChAT, cell size, and terminal arborization of those neurons are regulated by NGF (Sofroniew et al., 1990). The age-related reduction in NGF accessibility probably contributes to the pronounced vulnerability of cholinergic neurons 
to degeneration during aging and in Alzheimer's disease (Cooper et al., 1994; Scott et al., 1995).

The behavioral impairments which are associated with marked atrophic changes in the basal forebrain cholinergic system can be ameliorated by infusion of exogenous NGF. Intracerebroventricular infusion of NGF prevents the memory loss and degeneration of cholinergic neurons in septum and diagonal band following fimbria-fornix transections in rats (Will \& Hefti, 1985; Williams et al., 1986; Kromer 1987; Montero \& Hefti, 1989; Tuszynski et al., 1990; Koliatsos et al., 1991a) and in nonhuman primates (Koliatsos et al. 1991b; Tuszynski et al., 1991; Kordower et al., 1994). In aged rats, intraventricular infusions of NGF reverse cholinergic neuronal atrophy in the basal forebrain and the concomitant memory impairment (Fischer et al., 1987; 1991; Markowska et al., 1994; MartinezSerrano et al., 1995; 1996; Backman et al., 1996; Castel-Barthe et al., 1996), suggesting that age-related pathological brain dysfunction might be ameliorated by treatment with neurotrophic factor.

Most of earlier studies usually estimated degenerative or atrophic changes in morphology of the cholinergic neurons. However, recently attention has been focused on the idea that, during normal aging, cholinergic neurons do not die at first but undergo phenotypic changes (Smith et al., 1999) due to disordered neurotransmitter biosynthesis. Age-related reduction in ChAT-immunoreactivity was often interpreted as indicative of cell atrophy or death but age-dependent loss of enzyme activity, which could occur without true cell degeneration, is also possible. In aged rats, infusion of NGF could reverse age-related impairment in ChAT expression rather than prevent acute degeneration of neuronal cell bodies per se. Therefore, the present study was undertaken to examine the specificity and magnitude of the age-associated changes in characteristics of the basal forebrain cholinergic neurons in a normal non-selected population of senescent rats, and to determine the influence of exogenous NGF infusion on the morphology and physiology of the cholinergic system.

\section{MATERIAL AND METHODS}

Animals. Young and aged male Wistar rats were maintained in a colony room with food and water available ad libitum in the home cage. All studies were conducted using behaviorally uncharacterized animals from the same breeding colony. The rats were sub-divided randomly into treated and untreated groups. Each experimental group of rats is identified by an abbreviation describing the age (4 months old, and 28 months old rats at the time of morphological analysis) and type of treatment (con - control vehicle treated, and NGF - NGF-solution treated rats). Each treated and each control group consisted of five rats. The animal care procedures adhered to institutional guidelines and the Local Ethics Commission at the Nencki Institute.

Surgery. Rats were anesthetized with a mixture of $62.5 \mathrm{mg} / \mathrm{kg}$ ketamine and $3.2 \mathrm{mg} / \mathrm{kg}$ xylazine dissolved in $0.9 \%$ sterile saline. After anesthesia the rats were mounted in a small animal stereotaxic apparatus (David Kopf, Tujunga, CA, U.S.A.) with bregma and lambda in the same horizontal plane. In sterile conditions a burr hole was made $0.5 \mathrm{~mm}$ posterior to bregma and $1.6 \mathrm{~mm}$ lateral to the midline. A 28-gauge stainless steel cannula (4.5 mm dorsoventrally from dura) was lowered stereotaxically to the right lateral ventricle. The cannula was connected to subcutaneously implanted osmotic minipump (Alzet 2004, Alza Co., Palo Alto, CA, U.S.A.) via silastic tubing to secure one-month continuous delivery of substances. The pumps were filled with $220 \mu \mathrm{l} /$ pump either NGF (2.5S from mouse salivary gland, Boehringer, Mannheim; NGF groups) or vehicle solution (artificial cerebrospinal fluid containing 100 $\mu \mathrm{g} / \mathrm{ml}$ rat serum albumin; control groups). 
NGF was diluted in sterile artificial cerebrospinal fluid containing $100 \mu \mathrm{g} / \mathrm{ml}$ rat serum albumin. In an initial series of pilot experiments two doses of NGF (40 and $120 \mu \mathrm{g}$ as a total amount infused) were tested. On the basis of these studies a dose of $120 \mu \mathrm{g}$ was selected as the $0.5 \mu \mathrm{g} / \mu \mathrm{l}$ working concentration for intraventricular infusion to be used in the main experiment.

Chloromycetin sodium succinate (chloramphenicol, 1\% solution) was applied to the exposed skull and scalp prior to closure to limit local infection; lidocaine was applied locally to the scalp to lessen pain. Antibiotic G penicillin (bicicllin, $300000 \mathrm{U} / \mathrm{ml}$ ) and $5 \mathrm{ml}$ of sterile isotonic saline was injected subcutaneously to prevent infection and dehydration during recovery.

Tissue preparation. Animals were deeply anesthetized with Nembutal and the perfusion procedure was begun when all reflex responses to cutaneous stimulation were absent. Tissues were fixed by intraaortic perfusion with $0.9 \% \mathrm{NaCl}$ followed by a mixture of $4 \%$ paraformaldehyde and $15 \%$ picric acid in $0.1 \mathrm{M}$ phosphate buffer, $\mathrm{pH} 7.4$, and then followed by cold phosphate-buffered $5 \%$ glycerol with $2 \% \mathrm{Me}_{2} \mathrm{SO}$. The brains were removed and placed for $1 \mathrm{~h}$ in the fixative solution and then immersed for cryoprotection in 10\% followed by $20 \%$ glycerol $+2 \% \mathrm{Me}_{2} \mathrm{SO}$. For immunohistochemical analysis, brains were positioned in a brain matrix (BAS Inc., Lafayette U.S.A.) to evenly sliced into uniform blocks. Sections were cut coronally through the forebrain at $40 \mu \mathrm{m}$ thickness with a freezing stage microtome. Sixty consecutive sections were collected throughout the basal forebrain region (from $0.48 \mathrm{~mm}$ anterior to $-2.12 \mathrm{~mm}$ posterior to bregma (Paxinos \& Watson, 1997)) of each rat. From five series of the sections collected, one set of twelve was processed for ChAT immunoreactivity (ChAT-ir), the second set for $\mathrm{p} 75^{\mathrm{NTR}}$ immunoreactivity (p75 ${ }^{\text {NTR }}$-ir), the third for Cresyl Violet Nisslstaining, and the fourth for histochemical detection of acetylcholinesterase (AChE), and the fifth corresponding series of sections were stored at $-20^{\circ} \mathrm{C}$ in a cryoprotective solution as a reserve. The results of earlier studies (Smith et al., 1993; Smith \& Booze, 1995) revealed that no age-related changes in distribution of ChAT-ir cells were found along the anterior-posterior axis of the main basal forebrain (BF) areas. Based on these findings, the same number of stored brain sections from both young and aged animals was taken for the analysis.

Immunohistochemistry. For immunohistochemical determination of ChAT, a monoclonal antibody commercially supplied by Boehringer Mannheim (Germany) was used at $10 \mu \mathrm{g} / \mathrm{ml}$ dilution. The free-floating sections were incubated in Tris/HCl buffer with the primary antibody, with continuous agitation at room temperature overnight and subsequently were similarly incubated in a goat anti-rat biotin conjugated antibody (ICN Immunobiologicals, Irvine, CA, U.S.A.) for $1 \mathrm{~h}$ followed by peroxidase conjugated streptavidin (The Binding Site Lmt., England) for $1 \mathrm{~h}$. Following a brief ( $5 \mathrm{~min}$ ) reaction with $0.05 \%$ diaminobenzidine (DAB) in the presence of $0.01 \%$ hydrogen peroxide the sections were mounted on glass microscope slides, air-dried, dehydrated in alcohol/xylene serial solutions and coverslipped with permanent mounting media. After each incubation sections were washed 3 times for $5 \mathrm{~min}$. For p $75^{\text {NTR }}$, a rat monoclonal anti-nerve growth factor-receptor antibody (Boehringer Mannheim, Germany) was adjusted to a working concentration 5 of $\mu \mathrm{g} / \mathrm{ml}$. As above, the sections were incubated with agitation at room temperature overnight with the primary antibody, subsequently incubated in a biotinylated sheep anti-mouse immunoglobulin solution (The Binding Site Lmt., England) for $1 \mathrm{~h}$ and then in peroxidase conjugated streptavidin. The peroxidase was visualized with DAB. Controls were routinely run in the absence of primary antibodies in the first step as a safeguard against nonspecific staining by the primary antibody. 
Histochemistry. Target areas of the cholinergic BF neurons, such as the hippocampus, the olfactory bulb, the cortex and the amygdala, displayed a high density of AChE-positive fibers. AChE is generally used as a marker for putative cholinergic cortical fibers in rodent and nonhuman primate brain. Many studies indicated that, in most cortical areas, the pattern of AChE-positive fiber staining is similar to that of ChAT-ir fiber staining (e.g. Lysakowski et al., 1989; Baskerville et al., 1993). Thus, also in the present study, the histochemical reactivity of $\mathrm{AChE}$ was used as a marker for cholinergic projection to the cortex. To illustrate the data obtained, an example of somatic sensorimotor cortex was presented. In addition, detection of AChE activity, which in basal forebrain is predominantly localized to the cholinergic cells, served as an additional control of the presence of cholinergic neurons in the BF.

AChE was estimated by histochemical method of Geneser-Jansen \& Blackstad (1971). Sections were incubated in the reaction media at room temperature for $5 \mathrm{~h}$. In control experiment, a second set of slices was processed in an incubation media with addition of either ethopropazine methosulphate $\left(10^{-5} \mathrm{M}\right)$ as selective pseudocholinesterases inhibitor or 1,5-bis(4-allydimethylammoniumphenyl)pentan-3-dibromide (BW284c51). The addition of ethopropazine did not affect fibre or cell body staining, while the histochemical reaction was completely blocked with BW284c51. Thus, formation of the reaction-product described in our studies below was due to the activity of specific cholinesterase (AChE). A computer image analysis was used for quantitation of the intensity of staining measured across the entire cortical depth.

Computer-assisted microscopic mapping and morphological analysis. For the final analysis, slide series from 5 animals of each group were selected as representative among the multiple series that were processed. Sections were viewed with a Nikon Optiphot mi- croscope equipped with an $\mathrm{x} / \mathrm{y}$ movementsensitive stage and video camera attached to an IBM PC Pentium. A computerized image analysis technique (MCID, Imaging Research Inc., Canada, digitizer and software) was used for the morphometric and densitometric analysis of ChAT- and p75-immunoreactive neurons in the medial septum (MS), in the vertical (VDB) and horizontal (HDB) limb of the diagonal band, in the substantia innominata (SI), and in the magnocellular basal nucleus (NBM). Identification of the investigated brain areas was confirmed by referring to the atlas of rat brain by Paxinos \& Watson (1997). The boundaries of the structures in the coronal plane were determined microscopically and marked on line drawings using a computer-aided X-Y plotting system. Counting of the number of neuronal profiles in each outlined area and measurements of their square area (morphometric parameter), as well as intensity of their staining (ROD - relative optical density, semiquantitative densitometric parameter developed by the software) was done at $400 \times$ magnification. All consecutive sections of each series were analyzed. The neuronal counts were summarized using the mean neuronal numerical density per unit area analyzed. Thus, data are presented as unmodified neuronal cells counts per region under study, which are mean values from serial consecutive brain sections of five rats in each group. For the morphometric analysis neurons were defined as immunolabeled cell bodies when the best in focus cell nucleus and one or two dendrites were well visible within the counting frame. These criteria were used to exclude from the analysis any population of non-complete remnants of neurons. Neuronal counts were performed by two independent observers (inter-observer correlation $\mathrm{r}=$ 0.81).

Statistical analysis. All data were analyzed by parametric methods and expressed as means \pm S.E.M. The morphometric and densitometric data was compared by two-way ANOVA followed by post-hoc Newman-Keuls 
test. The analysis was made using STATISTICA software at $P<0.05$ level of significance.

\section{RESULTS}

\section{General observations}

In the present study numerical responses of ChAT-immunoreactive (ChAT-ir) neurons in the basal forebrain differed from those noted for $\mathrm{p} 75$-immunoreactivity ( $\mathrm{p} 75$-ir). All animals showed a clear cytoplasmic immunoreactivity for $\mathrm{p} 75^{\mathrm{NTR}}$ receptor in $\mathrm{BF}$ neurons and their morphology appeared unchanged in aged rats. The cell bodies were densely stained, with tapering varicose dendrites forming an intensely stained neuropil (Fig. 1d, e, f). This was not the case with ChAT immunostaining.
While in the young adult group neurons stained well (Fig. 1a), in no rat from the 28-month-old control group well visible ChAT immunostaining was observed. The number of ChAT immunostainable neurons in 28-month-old rats was lower than in young adult group consisting $50-70 \%$ for the control. The remaining ChAT-ir cells appeared shrunken with markedly reduced neuropil staining (Fig. 1b). Infusion of NGF increased the number of ChAT-ir cells in the 28-month-old group to about $90 \%$ of that for young control (Fig. 1c). In all NGF treated animals of the aged group dense immunolabeling of ChAT-ir cells was observed. On the contrary, NGF did not influence the morphology of p75-ir cells in aged animals (Fig. 1f), which were labeled well irrespective of the treatment. The population of large neurons in the basal magnocellular nucleus of the aged rats

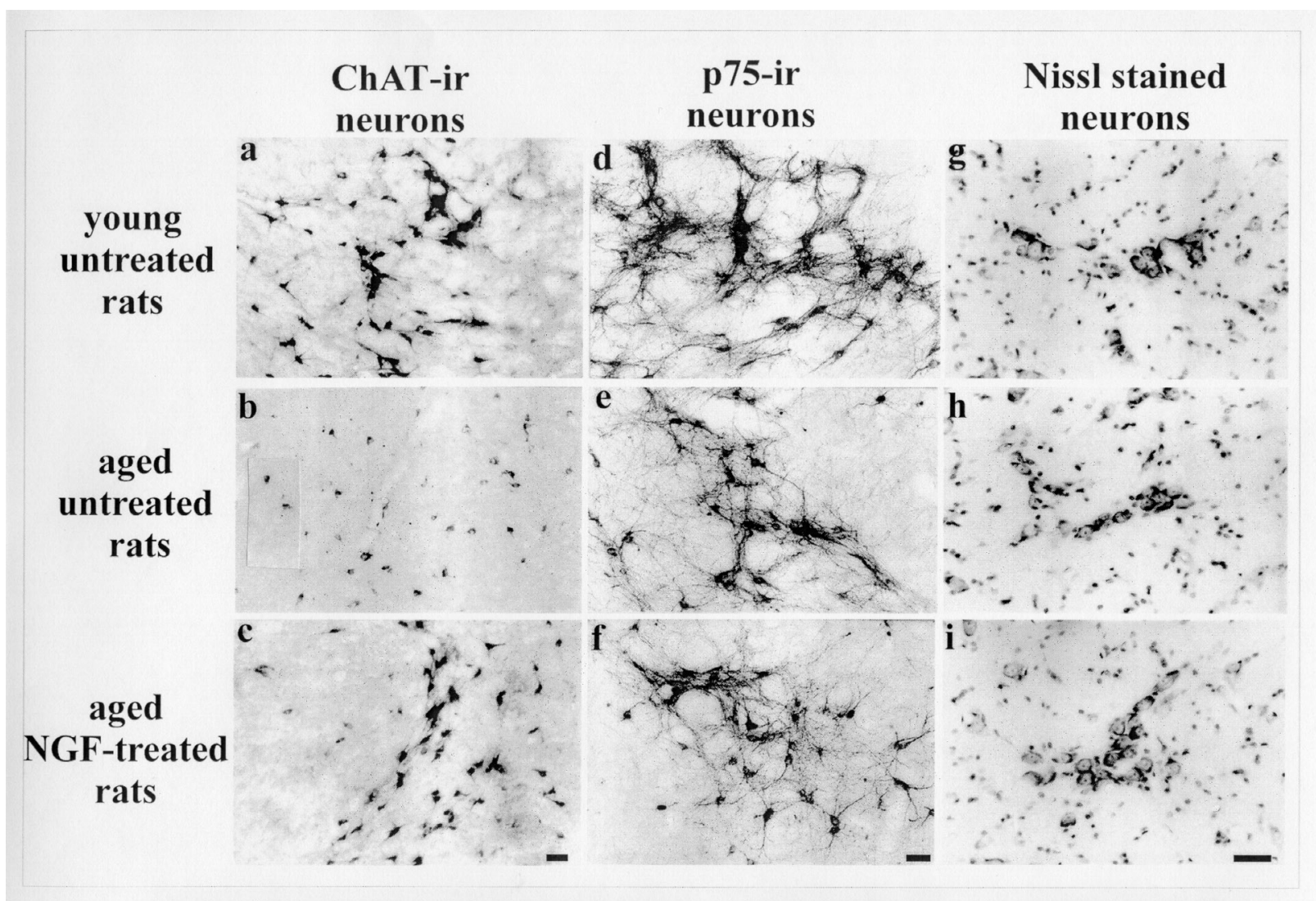

Figure 1. Photomicrographs of the magnocellular basal nucleus show the morphology of the cholinergic neurons in young $(\mathrm{a}, \mathrm{d}, \mathrm{g})$ and aged $(\mathrm{b}, \mathrm{e}, \mathrm{h})$ untreated rats and in aged NGF-treated animals (c, f, i).

Neurons were stained immunohistochemically to detect choline acetyltransferase (ChAT-ir, left vertical panel) and p75 low-affinity receptor of NGF (p75-ir, middle vertical panel) or were visualized by Nissl method with Cresyl Violet (right vertical panel). Bar $=20 \mu \mathrm{m}$. 
which had lost the ability to be stained for ChAT, still was labeled very well in Nissl staining and did not express distinct atrophic changes (Fig. 1g, h, i).

\section{Morphometry of basal forebrain neurons in young and aged untreated rats}

\section{ChAT-ir neurons}

In the 28-month-old control rats, the number of ChAT-ir cells was reduced as compared to the 4-month-old group. The loss of ChAT-ir neurons in aged rats was most pronounced in the SI-NBM region where a $67 \%$ reduction in the number of immunolabeled cells was observed (Fig. 2) $(P<0.0006)$. In all forebrain re-

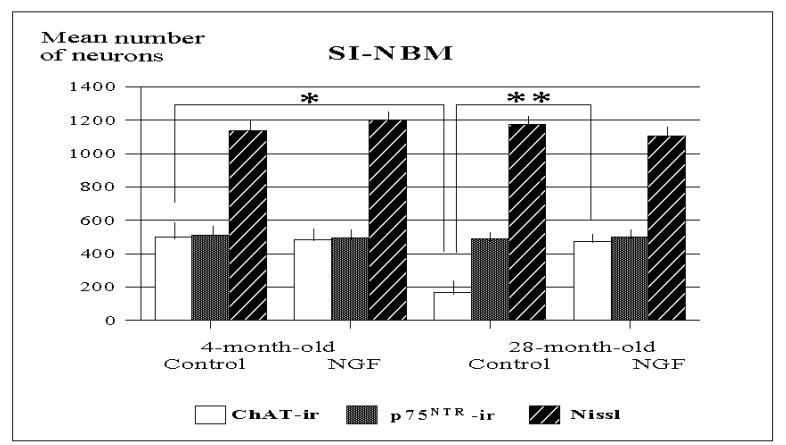

Figure 2. Mean number ( \pm S.E.M.) of ChAT- and p75-immunoreactive and Nissl stained neurons in the substantia innominata - magnocellular basal nucleus (SI-NBM) in young (4-month-old) and aged (28-month-old) untreated rats and in young (4-month-old) and aged (28-month-old) NGFtreated animals.

Difference in ChAT-ir cell number of young and aged untreated rats, significant at $P<0.0006(*)$; and in control and aged NGF-treated animals, significant at $P$ $<0.005(* *)$.

gions analyzed, the size of the remaining ChAT-ir cell bodies was significantly reduced in the aged control rats when compared with the young controls (Fig. 3A). The reduction in mean cross-sectional area of ChAT-ir neurons amounted to $11 \%$ in MS (137.2 \pm 33.8 vs 153.9 $\left.\pm 37.9 \mu \mathrm{m}^{2} ; \mathrm{n}=339 ; P<0.03\right), 23 \%$ in VDB $\left(148.5 \pm 38.1\right.$ vs $191.7 \pm 36.7 \mu \mathrm{m}^{2} ; \mathrm{n}=624 ; P$ $<0.0001), 19 \%$ in HDB (157.6 \pm 39.3 vs 194.2 $\left.\pm 43.2 \mu \mathrm{m}^{2} ; \mathrm{n}=962 ; P<0.001\right)$ and $17 \%$ in SI-NBM $\left(172.3 \pm 47.5\right.$ vs $206.1 \pm 42.7 \mu \mathrm{m}^{2}$; n = 683; $P<0.01)$.

The measurement of the densitometric parameter, the relative optical density (ROD) of immunolabeling (Fig. 3B), revealed an even more essential difference in morphology of ChAT-ir cells between young and aged control rats than the analysis of cell size. Aging resulted in a significant reduction in the intensity of immunostaining for ChAT in all BF structures. The overall decrease in ROD of the aged rats when compared with the young ones was $35 \%$ in MS $(0.31 \pm 0.08$ vs $0.47 \pm 0.09 ; P$ $<0.0002), 41 \%$ in $\operatorname{VDB}(0.19 \pm 0.07$ vs $0.32 \pm$ $0.07 ; P<0.00006), 25 \%$ in HDB $(0.28 \pm 0.06$ vs $0.37 \pm 0.1 ; P<0.001$ ) and $35 \%$ in SI-NBM (0.25 \pm 0.05 vs $0.38 \pm 0.08 ; P<0.00003)$.

$\mathrm{p} 75^{\mathrm{NTR}}$-ir neurons

Different results were obtained with the p $75^{\text {NTR }}$ antibody, which selectively stains the cholinergic neurons in the basal forebrain structures. In the aged control rats no significant reduction in the number of p75-ir cells was observed in the SI-NBM region (Fig. 2). In addition, the mean cross-sectional area of p75-ir neurons did not differ significantly between aged and young control groups (MS = $153.9 \pm 30.6$ vs $162.5 \pm 32.9 \mu \mathrm{m}^{2} ; \mathrm{VDB}=$ $191.7 \pm 36.5$ vs $182.8 \pm 34.5 \mu \mathrm{m}^{2}$; $\mathrm{HDB}=$ $192.1 \pm 43.5$ vs $193.0 \pm 48.9 \mu \mathrm{m}^{2}$; SI-NBM = $192.8 \pm 38.9$ vs $210.0 \pm 48.0 \mu \mathrm{m}^{2}$ ) (Fig. $4 \mathrm{~A}$ ).

Quite comparable data were obtained from analysis of the ROD parameter, which describes the intensity of immunostaining for the $\mathrm{p} 75^{\mathrm{NTR}}$. The strong perikaryal immunoreactivity in the basal forebrain neurons was unchanged in the aged control rats when compared with the young ones (MS $=0.51 \pm 0.06$ vs $0.43 \pm 0.09 ; \mathrm{VDB}=0.32 \pm 0.05$ vs $0.35 \pm$ 0.07 ; $\mathrm{HDB}=0.37 \pm 0.08$ vs $0.38 \pm 0.08$; SI-NBM $=0.41 \pm 0.1$ vs $0.41 \pm 0.07$ ) (Fig. 4B). Moreover, visualization of neuronal morphol- 
ogy with the $\mathrm{p} 75^{\mathrm{NTR}}$ antibody revealed that the $\mathrm{BF}$ neurons of aged rats did not display any atrophic or degenerative changes.

Nissl stained neurons

The number of all Nissl-stained neurons in the SI-NBM region was quantified within the same anatomical boundaries within which ChAT-ir and p75-ir cells were counted. There was no significant decline in the number of Nissl-stained cell bodies in aged control rats compared with young subjects (Fig. 2). Careful analysis of Nissl-stained brain sections re-

\section{Reversibility of age-related morphological} changes in BF neurons by NGF treatment

The reduction in the number of ChAT-ir neurons in aged rats was partially or completely reversed by chronic NGF infusion. The effect of NGF was observed not only on the side of the neurotrophic factor infusion (right hemisphere), but also in the contralateral hemisphere (not shown). In aged NGF-treated rats the number of ChAT-ir cell bodies, quantified as means per unit area of SI-NBM, was restored to about $95 \%$ of values in young untreated controls, an amount that did not differ

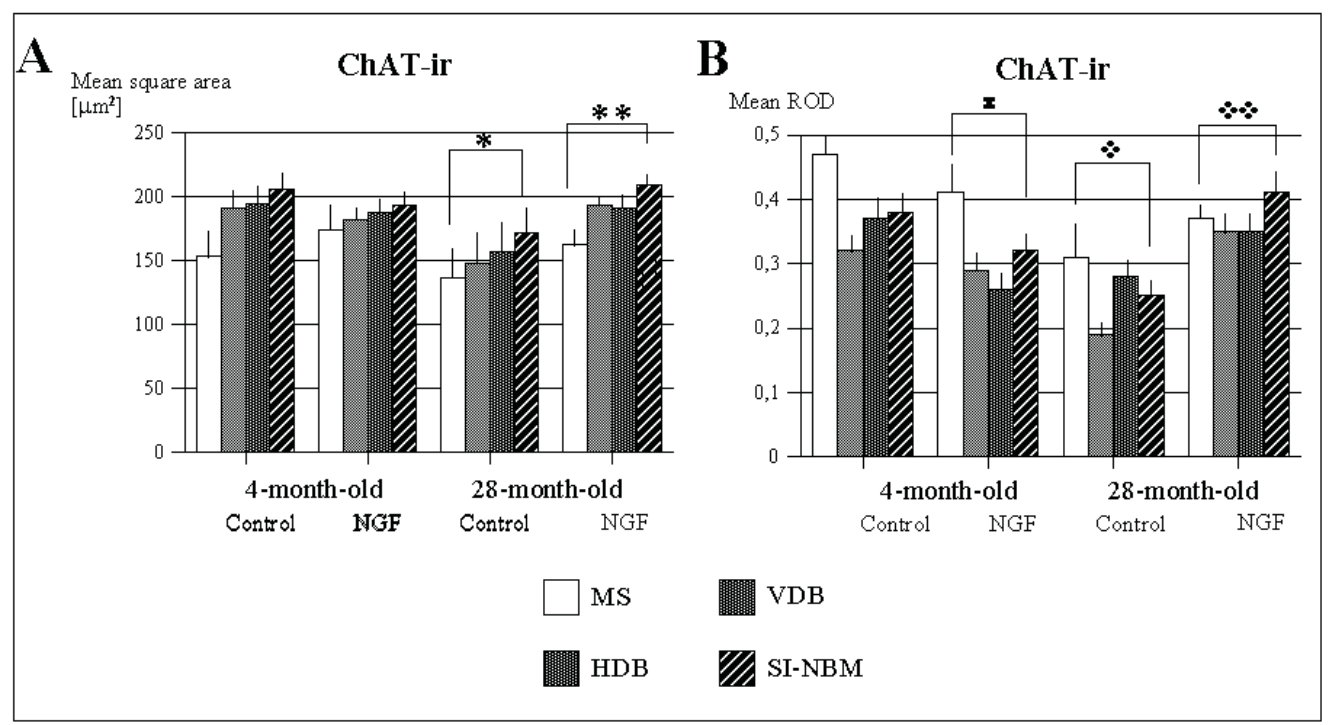

Figure 3. Mean cross-sectional area (A) and relative optical density (ROD) (B) ( \pm S.E.M.) of ChAT-immunoreactive neurons in young (4-month-old) and aged (28-month-old) untreated rats and in young (4-month- old) and aged (28-month-old) NGF-treated animals.

The data were compared in four basal forebrain regions: the medial septal nucleus (MS), the vertical (VDB) and horizontal (HDB) limb of the diagonal band, and the substantia innominata - magnocellular basal nucleus (SI-NBM). Difference in mean cross-sectional area of young and aged untreated rats, significant at P (*) and of aged control and aged NGF-treated rats significant at $\mathrm{P}(* *)$; difference in mean ROD of young untreated and young NGF-treated rats; significant at $\mathrm{P}(\mathscr{H})$; difference in mean ROD of young and aged untreated rats significant at $\mathrm{P}(\boldsymbol{)})$ and of aged control and aged NGF-treated rats, significant at $\mathrm{P}(*)$.

vealed no signs of degeneration of large basal forebrain neurons (Fig. 1g, h, i). Although we did not observe any neuronal shrinkage or neuronal loss in any of the basal areas, on comparing young normal rats with aged ones, we cannot exclude the existence of relatively small quantitative differences in perikaryal size or neuronal density. between groups $(475.5 \pm 27.9$ vs $499.6 \pm$ 31.1). However, there was a significant difference in the number of ChAT-ir neurons between aged control and NGF-treated rats (208.5 \pm 29.7 vs $499.6 \pm 31.1 ; P<0.003)$, which exhibited an increase of $63 \%$ in neuronal number compared with untreated subjects (Fig. 2). 
The size of ChAT-ir neurons in aged NGF-treated rats was comparable with that of young control ones (Fig. 3A) and did not dif- cholinergic neurons of young 4-month-old rats. This reduction was about $13 \%$ in MS $(0.41 \pm 0.07$ vs $0.47 \pm 0.09 ; \mathrm{n}=434 ; P<$

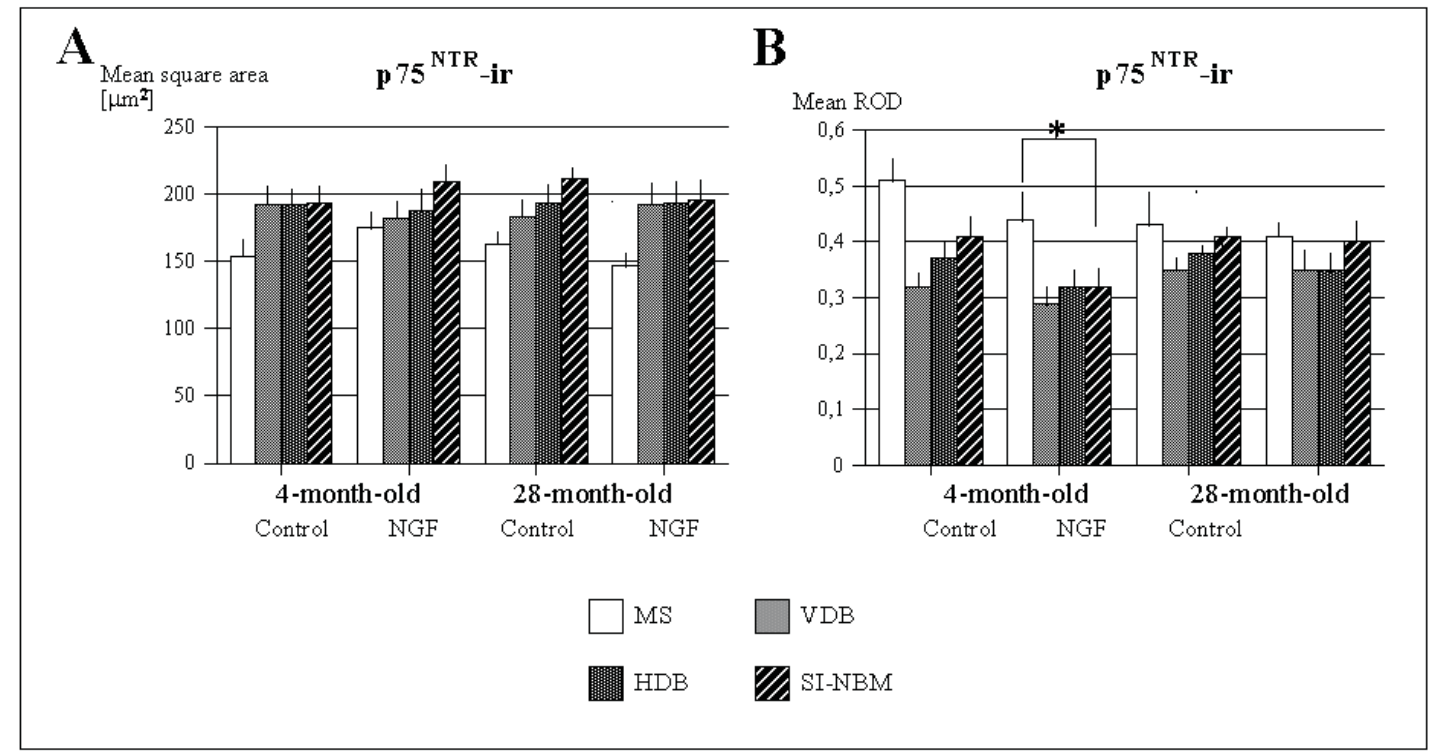

Figure 4. Mean cross-sectional area (A) and relative optical density (ROD) (B) ( \pm S.E.M.) of p75 ${ }^{\mathrm{NTR}}$-immunoreactive neurons in the basal forebrain structures in young and aged both control and NGF-treated rats.

Difference in mean ROD of young untreated and young NGF-treated rats significant at P. ?(*).

fer. Furthermore, the immunolabeled ChAT neurons of all tested regions were significantly larger in the 28-month-old rats treated with NGF than in the 28-month-old vehicle-treated controls. The overall increase in mean cross-sectional area was about $18 \%$ in MS $\left(162.5 \pm 33.8\right.$ vs $137.2 \pm 37.9 \mu \mathrm{m}^{2} ; \mathrm{n}=$ 239; $P<0.001), 30 \%$ in VDB (193.7 $\pm 38.1 \mathrm{vs}$ $\left.148.5 \pm 36.7 \mu \mathrm{m}^{2} ; \mathrm{n}=624 ; P<0.0001\right), 21 \%$ in $\operatorname{HDB}\left(191.1 \pm 43.3\right.$ vs $157.6 \pm 39.3 \mu \mathrm{m}^{2}$; $\mathrm{n}$ $=863 ; P<0.001)$ and $21 \%$ in SI-NBM $(208.9 \pm$ 42.3 vs $\left.172.3 \pm 47.5 \mu \mathrm{m}^{2} ; \mathrm{n}=786 ; P<0.001\right)$.

In aged rats treatment with NGF resulted in a significant increase in the intensity of immunostaining for ChAT. The enhancement in ROD values amounted to $17 \%$ in MS $(0.37$ \pm 0.09 vs $0.31 \pm 0.08 ; P<0.001), 46 \%$ in $\mathrm{VDB}$ ( $0.35 \pm 0.09$ vs $0.19 \pm 0.07 ; P<0.0006), 20 \%$ in $\operatorname{HDB}(0.35 \pm 0.09$ vs $0.28 \pm 0.06 ; P<0.001)$ and $40 \%$ in SI-NBM (0.41 \pm 0.09 vs $0.25 \pm$ $0.05 P<0.00002$ ) (Fig. 3B). In contrast, treatment with NGF decreased significantly the intensity of ChAT immunostaining in the basal
$0.002), 10 \%$ in $\operatorname{VDB}(0.29 \pm 0.08$ vs $0.32 \pm$ $0.07 ; \mathrm{n}=724 ; P<0.01), 30 \%$ in $\operatorname{HDB}(0.26 \pm$ 0.06 vs $0.37 \pm 0.1 ; \mathrm{n}=962 ; P<0.00003)$ and $16 \%$ in SI-NBM $(0.32 \pm 0.08$ vs $0.38 \pm 0.08$; $\mathrm{n}$ $=996 ; P<0.0003)$ as compared with the young untreated animals (Fig. 3B).

No difference in cell number and size between NGF-treated and vehicle control groups was observed when the measurements were done for p75-ir neurons (Fig. 2 and 4A). The NGF infusion did not change the intensity of p $75^{\text {NTR }}$ immunostaining, except for the aged rats (Fig. 4B). In young NGF-treated subjects the loss of p75 NTR immunoreactivity in the basal forebrain neurons matched the loss of ChAT immunoreactivity and was statistically significant. The overall decrease in ROD was $14 \%$ in $\mathrm{MS}(0.44 \pm 0.09$ vs $0.51 \pm 0.06 ; P<$ $0.01), 10 \%$ in $\operatorname{VDB}(0.29 \pm 0.07$ vs $0.32 \pm 0.05$; $P<0.02), 14 \%$ in $\operatorname{HDB}(0.32 \pm 0.08$ vs $0.37 \pm$ $0.08 ; P<0.01)$, and $22 \%$ in SI-NBM $(0.32 \pm$ 0.07 vs $0.41 \pm 0.1 ; P<0.004)$. 
As in untreated rats, the number of Nissl-stained neurons of SI-NBM in young and aged NGF-treated rats did not differ significantly.

\section{Acetylcholinesterase (AChE) fiber staining in brain cortex}

Figure 5 shows the results of AChE staining in the forelimb (S1FL) and hindlimb (S1HL) areas of parietal cortex in young and aged untreated rats and in NGF-treated animals. In young control rats three AChE active bands were observed: a superficial band in layer I, a moderately dense band within layer III, and a third band, thicker and dark, corresponding to the layer V-VI (Fig. 5B, in the left vertical panel). The pattern of $\mathrm{AChE}$ labeling in the aged control rats differed from that of young animals. Namely, although three bands of staining distributed in layer I, III, and V-VI were also distinguished, their overall intensity was clearly lower than that in the young rats (Fig. 5B, in the middle vertical panel). Intraventricular infusion of NGF enhanced the intensity of AChE staining in parietal cortex of aged rats in which three relatively dense bands of AChE activity were observed (Fig. $5 \mathrm{~B}$, in the right vertical panel). There were no pronounced changes in the intensity of AChE staining in NGF-treated young rats compared with the untreated animals (not shown).

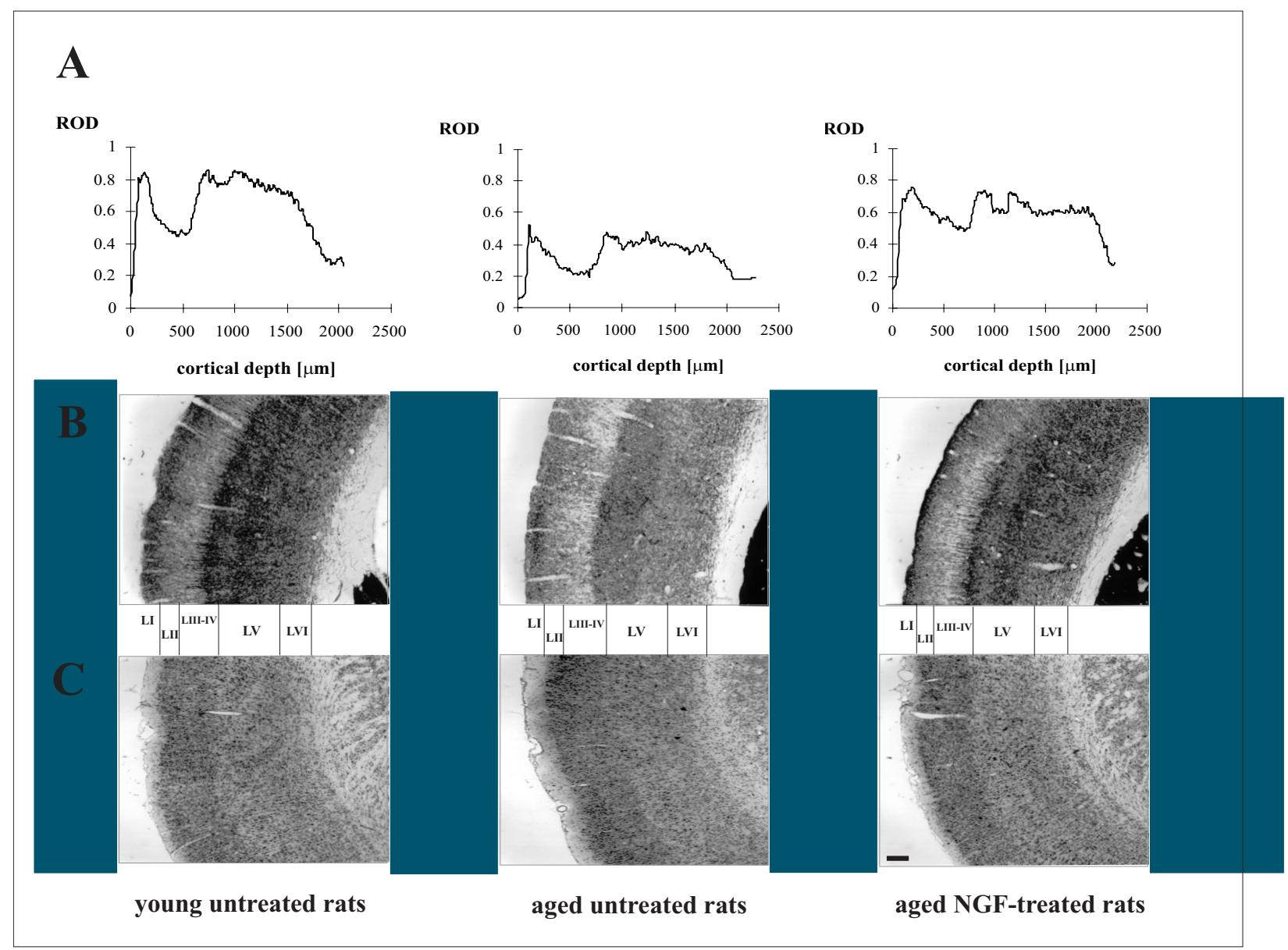

Figure 5. Distribution of acetylcholinesterase containing fibers through the somatic sensorimotor cortex (area S1HL and S1FL) in young and aged untreated and aged NGF-treated rats.

The laminar pattern of enzyme activity in cortical layers (B) is reflected by relative optical density (ROD) measured through the cortex with an image processing system (A). Photomicrographs of adjacent Nissl stained sections depicting cortical lamination of area S1HL-S1FL are included for reference (C). To match correctly cortical lamination in (B) Nissl stained sections were placed as mirror images. Bar $=200 \mu \mathrm{m}$. 


\section{DISCUSSION}

In the present study we focused on the morphology of the neuronal elements of the basal forebrain cholinergic system in a normal population of non-selected aged rats. In the 28-month-old control rats, ChAT positively stained neurons showed significant decrease of both cell size and cell number. The intensity of ChAT immunostaining was also lower in aged rats. However, it should be emphasized that the population of large neurons in the basal forebrain of aged rats, which had lost the ability to ChAT staining was still labeled very well for $\mathrm{p} 75^{\mathrm{NTR}}$ receptor and did not express distinct atrophic changes of cell bodies and processes. These observations were confirmed also by analysis of Nissl staining. Thus, both our ChAT-ir and p75-ir studies provide evidence for survival of the basal cholinergic neurons in aged rats.

The concept that cortical neurons are lost with age and that this was a basis of cognitive decline, was embedded in our knowledge for years. However, the reported counts of the cells in the cortex (Cragg, 1975; Pakkenberg \& Gundensen, 1997; Leuba \& Kraftsik, 1994; Gomez-Isla et al., 1996; Double et al., 1996) show that very few cells are lost during normal aging. In the studies of Pakkenberg \& Gundensen (1997) on humans, which covered the age range from 20 years to 90 years, only $10 \%$ of all neocortical neurons were lost over the life span in either sexes. Similarly, when comparisons were made with laboratory animals, primates (Herndon et al., 1998; Peters, 1997) and rodents (Pugnaloni et al., 1998), there is no strong evidence to support the concept that significant numbers of neurons are lost from cerebral cortex with age. Instead, it appears that cortical neurons are largely preserved. Thus, the cognitive deficits that arise during normal aging in humans, in non-human primates, and rodents could not be linked with an overall loss of cortical neurons.

However, it cannot be ruled out that there may be a dramatic loss of one of the specific populations of cortical neurons or neurons in non-cortical structures of the brain, which are important for learning and memory. Among these structures, basal forebrain cholinergic neurons have been extensively studied, particularly because of their degeneration during Alzheimer's disease (for example see Quirion, 1993). These cholinergic neurons project to the entire cortical mantle where they have been proposed to exert an integrative influence on information processing in the neocortex. Indeed, the telencephalic cholinergic complex is one of the most diffusely projecting neuronal systems in the brain, and it is generally considered an important central integrator in cognitive brain function. The loss of cortical cholinergic innervation during aging has been attributed to the loss of cholinergic cell groups present in the basal forebrain (Fischer et al., 1987; 1989; 1991; Vogels et al., 1990; Chen \& Gage, 1995). Some recent immunohistochemical studies on the BF report, however, on only changes in size of the neurons (Backmann et al., 1996). On the other hand, atrophy of these cells has been described (Martinez-Serrano et al., 1996; Smith et al., 1999).

The results of the current experiments are in general agreement with previous studies indicating that the integrity of basal forebrain cholinergic neurons is destroyed in aged rodents. Such earlier studies which were based on AChE histochemical localization or ChAT immunoreactivity (Kromer, 1987; Rosenberg et al., 1988; Cuello et al., 1989; Fischer et al., 1987; 1991) have usually reported the decline in the markers associated with perikarya of neurons, and concluded that this led to neuronal atrophy or death. However, based on the evidence presented above, it seems unjustified to conclude that a significant portion of cholinergic neurons degenerates with age. Cell shrinkage and reduction in cell number was observed only for ChAT immunostained neurons but not for $\mathrm{p} 75^{\mathrm{NTR}}$ stained neurons. It is notable that $\mathrm{p} 75^{\mathrm{NTR}}$ is expressed mainly, although not exclusively, by cholinergic neu- 
rons in the basal forebrain (Pioro \& Cuello, 1990) and that BF level of $\mathrm{p} 75^{\mathrm{NTR}}$ protein or its mRNA is not changed in old age or in Alzheimer's disease (Mufson et al., 1999; Cooper et al., 1994). Thus, immunostaining for $\mathrm{p} 75^{\mathrm{NTR}}$ could serve as a more than marker of cholinergic neurons. In agreement with those evidences, our data strongly suggest that forebrain cholinergic neurons do not lose their morphological integrity on aging. Apparent cell atrophy or cell loss reported earlier might have been wrongly identified on the basis of phenotypic changes in histochemical markers that do not detect true boundaries of the cell. Cell shrinkage and staining intensity can change independently during aging. Our results seem to indicate that senile impairment of the cholinergic system in rats concerns an age-related loss of choline acetyltransferase expression and that the possible down-regulation of ChAT could not lead to neuronal death.

Early studies led to the conclusion that there was a significant loss of neurons with age in subcortical structures. However, recent studies on aging in rats seem to confirm our presented results. There are indications that also neurons in the brain structures others than neocortex are largely preserved with age although their function is changed. Rapp \& Gallagher (1996) counted neuron numbers of representative samples of the entire hippocampus of behaviorally tested aged rats, and they reported that there was no age-related loss of neurons, even in the rats with the greatest age-related behavioral impairments. Hippocampal cell numbers were also evaluated in young and aged rats submitted to chronic unpredictable stress or corticosterone treatment (Sousa et al., 1998). Neither stress nor treatment with corticosterone was found to result in significant cell losses in any division of the hippocampal formation, either in young or aged rats; likewise, neither treatment produced significant volumetric differences. Moreover, the numbers of neurons did not differ in the two age groups of experimen- tal rats. Age-related morphological and functional changes were also studied in the medial mamillary nuclei of the hypothalamus (Begega et al., 1999). The number of neurons and glial cells remained unchanged with aging but there was an age-dependent reduction in medial mamillary nuclei volume and a decrease of neuronal activity and protein synthesis in this region. Similarly, in rats examined between the age of 3 and 23 months, no loss of cells was observed in cerebellum (Huang et al., 1999). Nevertheless, serious morphological changes pointing to functional losses were found. The cerebella of aged rats lost $30 \%$ of the thickness of the molecular layer, $60 \%$ of the length of parallel fibers, and $80 \%$ of the synaptic varicosities along parallel fibers.

Since the first demonstration of the rescue of degenerating basal forebrain cholinergic neurons (Hefti et al., 1984) by exogenously applied NGF a great many studies have confirmed this biological activity in a number of species including primates (Liberini \& Cuello, 1994). The results with rats, to which NGF was administered directly into the ventricle via minipumps, coincide with other studies (Kromer, 1987; Rosenberg et al., 1988; Cuello et al., 1989; Fischer et al., 1991) suggesting that the target-derived trophic factor is important for maintenance of the basal forebrain cholinergic projection system. Age-related decline in the number and size of ChAT-immunoreactive neuron, and, particularly, in the intensity of their staining were reversed by NGF infusion in all experimental subjects. The effect of NGF on the number and size of detectable ChAT-ir neurons in the basal forebrain of aged rats suggests that improvement by NGF was not related to survival of BF neurons but to a more specific action of NGF, such as more pronounced cholinergic phenotype of those neurons. NGF-mediated increase in the ChAT activity was first found in cell cultures prepared from fetal or neonatal rat septum (Gnahan et al., 1983; Hatanaka et al., 1988; Takei et al., 1988). Further studies have dem- 
onstrated that the intraventricular administration of NGF increases the ChAT activity in the basal forebrain of neonatal rats (Mobley et al., 1989). In adult animals NGF promotes neurotransmitter synthesis by enhancement of ChAT in BF cholinergic neurons (Williams et al., 1989; Dekker et al., 1992), probably at both the transcriptional and posttranslational level. NGF action on neurons exerted by regulation of nuclear gene expression is well established (e.g. Lorenzi et al., 1992). In addition, increased ChAT expression after NGF treatment correlated with age (Williams, 1991). Our data together with the previous reports raise the interesting possibility that availability of NGF plays a critical role in maintenance of phenotype fate of the NGF responsive cholinergic neurons during aging. It seems possible, that following nerve growth factor administration ChAT enzyme levels are reexpressed or increased. Moreover, the present study demonstrated that NGF can restore not only the ChAT expression in BF cholinergic neurons but also their cholinergic projection to the cortex, as shown by AChE histochemical measurement. In untreated aged rats, a number of network of AChE-positive cortical fibers was markedly reduced in the cortical areas. However, after administration of NGF the pattern of cortical AChE activity resembled that of young rats. Therefore, we conclude that, in aged rats, the cholinergic cells are not dying or becoming atrophic but rather are in a quiescent state.

The observation that infusion of NGF reverses the quiescent state of cholinergic neurons might suggest that a local deficit of the trophic factor is, at least, partly responsible for deterioration of cholinergic phenotype and cortical projection of those neurons. However, there is no consistent loss of NGF or NGF mRNA during aging or in dementia of Alzheimer's type (Hellweg \& Hartung, 1990; Hellweg et al., 1990). It is possible that impairment with age of axonal transport, as observed in peripheral (Caselli et al., 1999; Lopez et al., 1998; Ma et al., 2000) and septohippocampal (Linke \& Frotscher, 1993) nerves, can influence the availability of NGF, which is delivered to the cholinergic perikarya by retrograde transport. In aged rats, substantially fewer (Cooper et al., 1994) basal forebrain cholinergic neurons take up and retrogradely transport NGF from its target region. In addition, expression of the high affinity NGF receptor, TrkA, is significantly reduced in the basal forebrain of the aged rats (Mufson et al., 1997; 1999). High affinity binding of NGF has been reported to be reduced in the cerebral cortex of aged rats (Alberch et al., 1991). Taken together, these findings suggest that certain basal forebrain cholinergic neurons in aged rats may undergo intrinsic changes, leading to a failure of NGF signaling and, in consequence to perturbations in cholinergic projection of those neurons. The sustained NGF production, unaltered or even increased in the aged brain appears to be unable to prevent this deterioration in the forebrain cholinergic nuclei, possibly because of a diminished capacity of the NGF-sensitive neurons to bind or transport NGF in age rats.

In the majority of young adult rats, infusion of NGF caused a decrease in the intensity of ChAT and $\mathrm{p} 75^{\mathrm{NTR}}$ immunostaining, however, did not influence the size of the cholinergic neurons. The neural basis of such an effect remains unclear. It may be due to different sensitivity of cholinergic neurons of normal adult rats to NGF as compared with that of aged animals. Alternatively, the exogenous application of NGF may lead to an excessive level of trophic factor in young subjects. This supraoptimal administration of NGF may be injurious for normal adult cholinergic neurons. Similar results were observed in behavioral studies (Markowska et al., 1994) in which NGF infusion impaired choice accuracy of young adult rats in the recent memory task and ameliorated age-related deterioration in learning of old rats.

In conclusion, our results indicate that, in rats, cholinergic neurons of the basal forebrain survive during aging, but are not detect- 
able by ChAT immunohistochemical method. NGF, when supplied locally to the brain tissue in high pharmacological doses, permits to evaluate the level of expression of ChAT in this tissue and exerts its improving effect on the cholinergic neurons even if administered to rat brain at a very late phase of aging.

We express our appreciation to Ewa Bednarczyk for her assistance in the surgical implantation of the osmotic minipumps, and to Sebastian Komorowski for his help in computer image analysis.

\section{R E F E R E N C E S}

Alberch, J., Perez-Navarro, E., Arenas, E. \& Marsal, J. (1991) Involvement of nerve growth factor and its receptor in the regulation of the cholinergic function in aged rats. J. Neurochem. 57, 1483-1487.

Allen, S.J., Dawbarn, D. \& Wilcock, G.K. (1988) Morphometric immunochemical analysis of neurons in the nucleus basalis of Meynert in Alzheimer's disease. Brain Res. 454, 275-281.

Altavista, M.C., Rossi, P., Bentivoglio, A.R., Crociani, P. \& Albanses, A. (1990) Aging is associated with a diffuse impairment of forebrain cholinergic neurons. Brain Res. 508, 51-59.

Backmann, C., Rose, G.M., Hoffer, B.J., Henry, M.A., Bartus, R.T., Friden, P. \& Granholm, A.-C. (1996) Systemic administration of nerve growth factor conjugate reverses age-related cognitive dysfunction and prevents cholinergic neuron atrophy. J. Neurosci. 16, 54375442 .

Baskerville, K.A., Chang, H.T. \& Herron, P. (1993) Topography of cholinergic afferents from the nucleus basalis of Meynert to representational areas of sensorimotor cortices in the rat. $J$. Comp. Neurol. 335, 552-562.

Begega, A., Cuesta, M., Rubio, S., Santin, L.J. \& Arias, J.L. (1999) Age-related changes of the nucleolar organizer regions without neuron loss in medial mamillary bodies (hypothala- mus) in old rats. Mech. Ageing Dev. 108, 113-125.

Caselli, U., Bertoni-Freddari, C., Paolini, R., Fattoretti, P., Casoli, T. \& Meier-Ruge, W. (1999) Morphometry of axon cytoskeleton at internodal regions of rat sciatic nerve during aging. Gerontology 45, 307-311.

Castel-Barthe, M.N., Jazat-Poindessous, F., Barneoud, P., Vigne, E., Revah, F., Mallet, J. \& Lamour, Y. (1996) Direct intracerebral nerve growth factor gene transfer using a recombinant adenovirus: Effect on basal forebrain cholinergic neurons during aging. Neurobiol. Disease 3, 76-86.

Cavicchioli, L., Flanigan, T.P., Vantini, G., Fusco, M., Polato, P., Tofano, G., Walsh, F.S. \& Leon, A. (1989) NGF amplifies expression of NGF receptor messenger RNA in forebrain cholinergic neurons of rats. Eur. J. Neurosci. 1, $258-262$.

Chen, K.S. \& Gage, F.H. (1995) Somatic gene transfer of NGF to the aged brain: Behavioral and morphological amelioration. J. Neurosci. 15, 2819-2825.

Cooper, J.D., Mufson, E.J. \& Friden, P.M. (1994) Reduced transport of $\left[{ }^{125} \mathrm{I}\right]$ nerve growth factor by cholinergic neurons and down-regulated TrkA expression in the medial septum of aged rats. Neuroscience 62, 625-629.

Cragg, B.G. (1975) The density of synapses and neurons in normal, mentally defective and aging human brains. Brain 98, 81-90.

Cuello, A.C., Garofalo, L., Kenigsberg, R.L. \& Maynsinger, D. (1989) Gangliosides potentiate in vivo and in vitro effect of nerve growth factor on central cholinergic neurons. Proc. Natl. Acad. Sci. U.S.A. 86, 2056-2060.

Dani, S.U., Hori, A. \& Walter, G.F. (1997) Section III: Tissue and cellular changes; in Principles of Neuronal Aging, pp. 247-273, Elsevier, Amsterdam.

Dekker, A.J., Gage, F.H. \& Thal, L.J. (1992) Delayed treatment with nerve growth factor improves acquisition of a spatial task in rats with lesions of the nucleus basalis magnocellularis: evaluation of the involvement of different neu- 
rotransmitter systems. Neuroscience $\mathbf{4 8}$, 111-119.

Double, K.L., Halliday, G.M., Kril, J.J., Harasty, J.A., Cullen, K., Creasey, H. \& Broes, G.A. (1996) Topography of brain atrophy during normal aging and Alzheimer's disease. Neurobiol. Aging 17, 513-521.

Dravid, A.R. (1993) Deficits in cholinergic enzymes and muscarinic receptors in the hippocampus and striatum of senescent rats: Effect of chronic hydergine treatment. Arch. Int. Pharmacodyn. 264, 195-202.

Fischer, W., Wictorin, K., Björklund, A., Williams, L.R., Varon, S. \& Gage, F.H. (1987) Amelioration of cholinergic neuron atrophy and spatial memory impairment in aged rats by nerve growth factor. Nature 329, 65-68.

Fischer, W., Gage, F.H. \& Björklund, A. (1989) Degenerative changes in forebrain cholinergic nuclei correlate with cognitive impairments in aged rats. Eur. J. Neurosci. 1, 34-45.

Fischer, W., Björklund, A., Chen, K. \& Gage, F.H. (1991) NGF improves spatial memory in aged rodents as a function of age. J. Neurosci. 11, 1889-1906.

Flood, D.G. \& Coleman, P.D. (1988) Neuron numbers and size in aging brain: Comparisons of human, monkey, and rodent data. Neurobiol. Aging 9, 53-463.

Francis, P.T., Cross, A.J. \& Bowen, D.M. (1994) Neurotransmitter and neuropeptides; in Alzheimer's Disease (Terry, R.D., Katzman, R. \& Bick, K.L., eds.) pp. 156-197, Raven Press, New York.

Gallagher, M. \& Pelleymounter, M.A. (1988) An age-related spatial learning deficit: Choline uptake distinguishes "impaired" and "unimpaired” rats. Neurobiol. Aging 9, 363-369.

Geneser-Jansen, F.A. \& Blackstad, T.W. (1971) Distribution of acetylcholinesterase in the hippocampal region of the guinea pig. $Z$. Zellforsch. Microscop. Anat. 114, 460-481.

Gilad, G.M., Rabey, J.M., Tizabi, Y. \& Gilad, V.H. (1987) Age-dependent loss and compensatory changes of septohippocampal cholinergic neurons in two rat strains differing in longevity and response to stress. Brain Res. 436, 311-322.

Gibbson, G.E. \& Peterson, C. (1981) Brain acetylcholine synthesis declines with senescence. Science 213, 674-676.

Gnahan, H., Hefti, F., Heumann, R., Schwab, M. \& Thoenen, H. (1983) NGF-mediated increase of choline acetyltransferase (ChAT) in the neonatal forebrain: Evidence for a physiological role of NGF in the brain. Dev. Brain Res. 9, 45-52.

Gomez-Isla, T., Price, J.L., Mckeel, D.W., Morris, J.C., Growdon, J.H. \& Hyman, B.T. (1996) Profound loss of layer II entorhinal cortex neurons occurs in very mild Alzheimer's disease. J. Neurosci. 16, 4491-4500.

Hatanaka, H., Tsukui, H. \& Nihonmatsu, I. (1988) Developmental change in the nerve growth factor action from indication of choline acetyltransferase in promotion of cell survival in cultured basal forebrain cholinergic neurons from postnatal rats. Brain Res. 467, 85-95.

Hayashi, M. (1996) Neurotrophins and the primate central nervous system: A minireview. Neurochem. Res. 21, 739-747.

Hefti, F., Hartikka, J., Eckenstein, F., Gnahn, H., Heumann, R. \& Schwab, M. (1989) Nerve growth factor (NGF) increases choline acetyltransferase but not survival of fibre outgrowth of cultured fetal septal cholinergic neurons. Neuroscience 14, 55-68.

Hefti, F., Dravid, A. \& Hartikka, J. (1984) Chronic intraventricular injection of nerve growth factor elevate hippocampal choline acetyltransferase activity in adult rats with septohippocampal lesion. Brain Res. 293, 305-311.

Hellweg, R. \& Hartung, H.D. (1990) Endogenous levels of nerve growth factor (NGF) are altered in experimental diabetes mellitus: A possible role for NGF in the pathogenesis of diabetic neuropathy. J. Neurosci. Res. 26, 258-267.

Hellweg, R., Nitsch, R., Hock, C., Jaksch, M. \& Hoyer, S. (1990) Nerve growth factor and choline acetyltransferase activity levels in the rat brain following experimental impairment of cerebral glucose and energy metabolism. $J$. Neurosci. Res. 3, 479-486. 
Herndon, J.G., Tigges, J., Klumpp, S.A. \& Anderson, D.C. (1998) Brain weight does not decrease with age in rhesus monkeys. Neurobiol. Aging 19, 267-272.

Huang, C.M., Brown, N. \& Huang, R.H. (1999) Age-related changes in the cerebellum: Parallel fibers. Brain Res. 840, 148-152.

Knusel, B. \& Hefti, F. (1993) Multiple and interactive responses of central neurons to neurotrophic factors. Semin. Neurosci. 5, 259-267.

Koh, S., Chang, P., Collier, T.J. \& Loy, R. (1989) Loss of NGF receptor immunoreactivity in basal forebrain neurons of aged rats: Correlation with spatial memory impairment. Brain Res. 489, 397-404.

Koliatsos, V.E., Applegate, M.D., Knusel, B., Junard, E.O., Burton, L.E., Mobley, W.C., Hefti, F. \& Price, D.L. (1991a) Recombinant human nerve growth factor prevents retrograde degeneration of axotomized basal forebrain. Exp. Neurol. 112, 161-173.

Koliatsos, V.E., Clatterbuck, R.E., Nauta, W.H.J., Knusel, B., Burton, L.E., Hefti, F. \& Price, D.L. (1991b) Recombinant human growth factor prevents degeneration of basal forebrain cholinergic neurons in primates. Ann. Neurol. 30, 831-840.

Kordower, J.H., Winn, S.R., Liu, Y.T., Mufson, E.J., Sladek, J.R., Hammang, J.P., Baetge, E.E. \& Emerich, D.F. (1994) The aged monkey basal forebrain: rescue and sprouting of axotomized basal forebrain neurons after grafts of encapsulated cells secreting human nerve growth factor. Proc. Natl. Acad. Sci. U.S.A. 91, 10898-10902.

Korsching, S. (1986) The role of nerve growth factor in the CNS. Trends Neurosci. 11/12, $570-573$.

Kromer, L.F. (1987) Nerve growth factor treatment after brain injury prevents neuronal death. Science 235, 214-216.

Leuba, G. \& Kraftsik, R. (1994) Changes in volume surface estimate, three-dimensional shape and total numbers of neurons of the human primary visual cortex from midgestation until old age. Anat. Embryol. 190, 351-366.
Liberini, P. \& Cuello, A.C. (1994) Effects of nerve growth factor in primate models of neurodegeneration: Potential relevance in clinical neurology. Rev. Neurosci. 5, 89-104.

Linke, R. \& Frotscher, M. (1993) Development of rat septohippocampal projection: Tracing with DiI and electron microscopy of identified growth cones. J. Comp. Neurol. 332, 69-88.

Lopez, S.M., Perez-Perez, M., Marquez, J.M., Naves, F.J., Represa, J. \& Vega, J.A. (1998) p75 and TrkA neurotrophin receptors in human skin after spinal cord and peripheral nerve injury, with special reference to sensory corpuscles. Anat. Rec. 251, 371-383.

Lorenzi, M.V., Knusel, B., Hefti, F. \& Strauss, W.L. (1992) Nerve growth factor regulation of choline acetyltransferase gene expression in rat embryo basal forebrain cultures. Neurosci. Lett. 140, 185-188.

Lysakowski, A., Wainer, B.H., Bruce, G. \& Hersh, L.B. (1989) An atlas of the regional and laminar distribution of choline acetyltransferase immunoreactivity in rat cerebral cortex. $\mathrm{Neu}$ roscience 28, 291-336.

Ma, D., Himes, B.T., Shea, T.B. \& Fischer, I. (2000) Axonal transport of microtubule-associated protein B (MAP1B) in the sciatic nerve of adult rat: Distinct transport rates of different isoforms. J. Neurosci. 20, 2112-2120.

Mandel, R.J., Gage, F.H. \& Thal, L.J. (1989) Spatial learning in rats: Correlation with cortical choline acetyltransferase and improvement with NGF following NBM damage. Exp. Neurol. 104, 208-217.

Markowska, A.L., Koliatsos, V., Price, D. \& Olton, D.S. (1994) Behavioral effects of nerve growth factor (NGF) in young and aged rats. $J$. Neurosci. 14, 4815-4824.

Martinez, H.J., Dreyfus, C.F., Jonakait, G. \& Black, I.B. (1989) Nerve growth factor promotes cholinergic development in brain striatal cultures. Proc. Natl. Acad. Sci. U.S.A. 62, $7777-7781$.

Martinez-Serrano, A., Fischer, W. \& Björklund, A. (1995) Reversal of age-dependent cognitive impairments and cholinergic neuron atrophy by 
NGF-secreting neuronal progenitors grafted to the basal forebrain. Neuron 15, 473-484.

Martinez-Serrano, A., Fischer, W., Söderström, S., Ebendal, T. \& Björklund, A. (1996) Longterm functional recovery from age-induced spatial memory impairments by nerve growth factor gene transfer to the rat basal forebrain. Proc. Natl. Acad. Sci. U.S.A 93, 635-6360.

Mobley, W.C., Rutkowski, J.L., Tennekoon, G.I., Buchannan, K. \& Johnston, M.V. (1985) Choline acetyltransferase activity in striatum of neonatal rats increased by nerve growth factor. Science 229, 284-287.

Mobley, W.C., Woo, J.E., Edwards, R.H., Riopelle, R.J., Longo, F.M., Weskamp, G., Otten, U., Valleta, J.S. \& Johnson, M.V. (1989) Developmental regulation of nerve growth factor and its receptor in the rat caudate-putamen. $\mathrm{Neu}$ ron 3, 655-664.

Montero, C.N. \& Hefti, F. (1989) Intraventricular nerve growth factor administration prevents lesion-induced loss of septal cholinergic neurons in aging rats. Neurobiol. Aging 10, $739-743$.

Mufson, E.J., Lavine, N., Jaffar, S., Kordower, J.H., Quirion, R. \& Saragovi, H.U. (1997) Reduction in p140-TrkA receptor protein within the nucleus basalis and cortex in Alzheimer's disease. Exp. Neurol. 146, 91-103.

Mufson, E.J., Kroin, J.S., Sendera, T.J. \& Sobreviela, T. (1999) Distribution and retrograde transport of trophic factors in the central nervous system: Functional implications for the treatment of neurodegenerative diseases. Prog. Neurobiol. 57, 451-484.

Olton, D.S., Markowska, A.L., Voytko, M.L., Givens, B., Gorman, L. \& Wenk, G.L. (1991) Basal forebrain cholinergic system: A functional analysis; in The Basal Forebrain: Anatomy to Function (Napier, T.C., Kalivas, P.W. \& Hanin, I., eds.) Plenum Press, New York.

Pakkenberg, B. \& Gundensen, H.J. (1997) Neocortical neuron number in humans: Effect of sex and age. J. Comp. Neurol. 384, 312- 320.

Paxinos, G. \& Watson, C. (1997) The Rat Brain in Stereotaxic Coordinates. Academic Press, New York.
Peters, A., Morrison, J.H., Rosene, D.L. \& Hyman, B.T. (1998) Are neurons lost from the primate cerebral cortex during normal aging? Cerebral Cortex 8, 295-300.

Peters, A. (1997) A further evaluation of the effect of age on striate cortex of the rhesus monkey. Neurobiol. Aging 18, 29-36.

Pioro, E.P. \& Cuello, A.C. (1990) Distribution of nerve growth factor receptor-like immunoreactivity in the adult rat central nervous system. Effect of colchicines and correlation with the cholinergic system. Neuroscience 34, $57-87$.

Pugnaloni, A., Pallotti, F., Genova, M.L., Zucchini, C., Amati, S., Tesei, M., Biagini, G. \& Lenaz, G. (1998) Histomorphometric studies in rat cerebral cortex: Normal aging and cell loss. Cell Mol. Biol. 44, 597-604.

Quirion, R. (1993) Cholinergic markers in Alzheimer disease and the autoregulation of acetylcholine release. J. Psychiatr. Neurosci. 18, $226-234$.

Rama-Sastry, B.V., Janson, V.E., Jaiswal, N. \& Tayeb, O.S. (1983) Changes in enzymes of the cholinergic system and acetylcholine release in the cerebra of ageing male Fischer rats. Pharmacology 26, 61-72.

Rapp, P.R. \& Gallagher, M. (1996) Preserved neuron number in the hippocampus of aged rats with spatial learning deficits. Proc. Natl. Acad. Sci. U.S.A 93, 9926-9930.

Rosenberg, M.B., Friedman, T., Robertson, R.C., Tuszynski, M., Wolff, J.A., Breakefield, X.O. \& Gage, F.H. (1988) Grafting genetically modified cells to the damaged brain: Restorative effects of NGF expression. Science 242, $1575-1578$.

Schattemann, G.C., Gibbs, L., Lanahan, A.A, Claude, P. \& Bothwell, M. (1988) Expression of NGF receptor in the developing and adult primate central nervous system. J. Neurosci. 8, $860-873$.

Scott, S.A., Mufson, E.J., Weingarten, J.A., Shan, K.A. \& Grutcher, K.A. (1995) Nerve growth factor in Alzheimer's disease. Increased level throughout the brain coupled with declines in nucleus basalis. J. Neurosci. 15, 6213-6221. 
Smith, D.E., Roberts, J., Gage, F.H. \& Tuszynski, M.H. (1999) Age-associated neuronal atrophy occurs in the primate brain and is reversible by growth factor gene therapy. Proc. Natl. Acad. Sci. U.S.A. 98, 10893-10898.

Smith, M.L., Deadwyler, S.A. \& Booze, R.M. (1993) 3-D reconstruction of the cholinergic basal forebrain system in young and aged rats. Neurobiol. Aging 14, 389-392.

Smith, M.L. \& Booze, R.M. (1995) Cholinergic and gabaergic neurons in the nucleus basalis region of young and aged rats. Neuroscience $\mathbf{6 7}$, 679-688.

Snider, W.D. (1994) Function of the neurotrophins during nervous system development: What the knockouts are teaching us. Cell 77, 627-638.

Sofroniew, M.V. \& Cooper, J.D. (1993) Neurotrophic mechanisms and neuronal degeneration. Semin. Neurosci. 5, 285-294.

Sofroniew, M.V., Galletly, N.P., Isacson, O. \& Svendsen, C.N. (1990) Survival of adult basal forebrain cholinergic neurons after loss of target neurons. Science 247, 338-342.

Sousa, N., Almeida, O.F., Holsboer, F., PaulaBarbosa, M.M. \& Madeira, M.D. (1998) Maintenance of hippocampal cell numbers in young and aged rats submitted to chronic unpredictable stress. Comparison with the effects of corticosterone treatment. Stress 2, 237-249.

Springer, J.E., Tayrien, M.W. \& Loy, R. (1987) Regional analysis of age-related changes in the cholinergic system of the hippocampal formation and basal forebrain of the rat. Brain Res. 407, 180-184.

Strong, R., Hicks, P., Hsu, L., Bartus, R.T. \& Enna, S.J. (1990) Age-related alterations in the rodent brain cholinergic system and behavior. Neurobiol. Aging 10, 59-63.

Takei, N., Tsukui, H. \& Hatanaka, H. (1988) Nerve growth factor increases the intracellular content of acetylcholine in cultured septal neurons from developing rats. J. Neurochem. 51, $1118-1125$.

Thoenen, H., Bandtlow, C. \& Heumann, R. (1987) The physiological function of nerve growth fac- tor in the central nervous system: Comparison with the periphery. Rev. Physiol. Biochem. Pharmacol. 109, 145-178.

Tuszynski, M.H., Armstrong, D.M. \& Gage, F.H. (1990) Basal forebrain cell loss following fimbria/fornix transection. Brain Res. 508, 241-248.

Tuszynski, M.H., Sang, H., Yoshida, K. \& Gage, F.H. (1991) Recombinant human nerve growth factor infusions prevent cholinergic neuronal degeneration in the adult primate brain. Ann. Neurol. 30, 625-636.

Vogels, O.J., Broere, C.A., ter Laak, H.J., ten Donkelaar, H.J., Nieuwenhuys, R. \& Schulte, B.P. (1990) Cell loss and shrinkage in the nucleus basalis Meynert complex in Alzheimer's disease. Neurobiol. Aging 11, 3-13.

Whitehous, P.J., Price, D.L., Struble, R.G., Clark, A., Coyle, J.T. \& De Long, M.R. (1982) Alzheimer's disease and senile dementia: Loss of neurons in the basal forebrain. Science $\mathbf{2 1 5}$, 1237-1240.

Whittemore, S.R. \& Seiger, A. (1987) The expression, localization and functional significance of beta-nerve growth factor in the central nervous system. Brain Res. 12, 439-464.

Will, B. \& Hefti, F. (1985) Behavioral and neurochemical effects of chronic intraventricular injections of nerve growth factor in adult rats with fimbria lesions. Behav. Brain Res. 17, 17-24.

Williams, L.R., Varon, S., Peterson, G.M., Wictorin, K., Fischer, W., Björklund, A. \& Gage, F.H. (1986) Continuous infusion of nerve growth factor prevents basal forebrain neuronal death after fimbria fornix transection. Proc. Natl. Acad. Sci. U.S.A. 83, 92319235 .

Williams, L.R., Jodelis, K.S. \& Donald, M.R. (1989) Axotomy-dependent stimulation of choline acetyltransferase activity by exogenous mouse nerve growth factor in adult rat basal forebrain. Brain Res. 498, 243-256.

Williams, L.R. (1991) Hypophagia is induced by intracerebroventricular administration of nerve growth factor. Exp. Neurol. 113, 31-37. 